\title{
Research Paper: Investigating the Effect of Training With the Method of Simulation on the Knowledge and crossuark Performance of Nursing Students in the Pre-Hospital Triage
}

Roohollah Farhadloo ${ }^{1}$, Mahdi Kashani Nejad ${ }^{2}$, Mahsa Haji Mohammad Hoseini ${ }^{1}$, Mostafa Vahedian ${ }^{3}$, Mohammad Parvaresh Masoud $^{1 *} \mathbb{D}$

1. Department of Emergency Medicine, School of Medicine, Qom University of Medical Sciences, Qom, Iran.

2. Disaster and Emergency Medicine Management Center, Qom University of Medical Sciences, Qom, Iran.

3. Clinical Research Development Center, Qom University of Medical Sciences, Qom, Iran.

Article info:

Received: 03 Oct. 2017

Accepted: 14 Jan. 20118

\section{Keywords:}

Nursing students, Mockup model, Disasters, Triage
Citation: Farhadloo R, Kashani Nejad M, Haji Mohammad Hoseini M, Vahedian M, Parvaresh Masoud M. Investigating the Effect of Training With the Method of Simulation on the Knowledge and Performance of Nursing Students in the Pre-Hospital Triage. Health in Emergencies and Disasters Quarterly. 2018; 3(3): 123-130 . https://doi.org/10.29252/nrip.hdq.3.3.123

doi: : https://doi.org/10.29252/nrip.hdq.3.3.123 


\section{Introduction}

ccidents and medical emergencies are A important issues in the health system [1]. Some of these accidents are caused due to natural elements while some other events pertaining to accidents and medical emergencies, such as war, are man-made [2]. In 2012, the Asian continent was at the forefront of natural disasters and accounted for $86.3 \%$ of all the victims of such disasters [3]. In the meantime, the situation in Iran seems more sensitive because 77\% of Iran's cities are located on the path of earthquake faults and $35 \%$ are subject to clogged flood drains, storms and coastal waves [4]. In the absence of pre-planned mechanisms and management, disasters can result in vast human and financial losses. One of the important measures for crisis management is to evaluate all the victims of an accident in order to provide treatment and evacuate them to hospitals and examine their priority for distribution of the facilities [5]. The key to success in such conditions is triage [6].

Triage is derived from the Latin word 'Trier,' which means prioritization in providing care to patients who need treatment services when there is a shortage of facilities needed to provide concurrent services to all patients [7]. The goal of triage is to provide maximum emergency services under minimum facilities and in minimum time [8]. Over the past decades, numerous studies have shown that a triage suitable for injured patients has reduced mortality and improved resource utilization [9]. Various systems and approaches have been formed regarding the triage. One of these widely accepted and utilized systems is the Simple Triage And Rapid Transport (START) system [10].

Nurses, as the largest and most important healthcare group, are the first line of responders to the injured, particularly for carrying out the triage on the injured [11]. The triage nurse determines the clinical care priority of patients. Due to the important role and dynamics of the triage activities, the best and the most well-trained people should be selected for this task [12].

Clearly, with the advancement in science and technology, the only effective way to strengthen the nurses for preventing complications of accidents and disasters is to help them acquire knowledge and apply it in practice [13]. Unfortunately, studies conducted in Iran and the world have shown a lack of preparedness in nurses for carrying out the triage in the case of accidents and medical emergencies [14, 15]. In Iran, nurses do not receive comprehensive training for the triage system during their academic studies. Moreover, triage training in emergency wards is limited to a two-hour session [7].

Various studies have evaluated the level of knowledge and information of the nurses and nursing students regarding triage and have reported poor and less than average knowledge level [16-20]. The results of the study by Tabatabai indicated that the median score of knowledge of nursing students was $9 \pm 2.7$, which indicates the low knowledge of the students about triage [18]. Similarly, in the research by Malekshahi, the nurses' knowledge about triage was reported to be average [21]. For this reason, most educational centers are seeking to develop educational methods that can extend and raise the clinical decision-making capacities and the sustainable learning of nurses and nursing students [2]. One of these educational methods is training through simulation that attempts to display some of the physical or abstract systemic behavioral aspects by means of the behavior of another system. The main purpose of application of simulation in health care is to prepare the nursing students to deal with clinical situations [22].

Considering the importance of the issue and the existing gap in knowledge and theory with the performance, and the necessity of proper and correct conduct of triage and considering that the roads of the city of Qom during many times of the year due to various occasions are among the busiest roads in the country with regard to automobile traffic and on the other hand as a province adjoining the capital of the country, the preparedness of medical treatment personnel for quicker and more efficient management and organization to attend to and care for the victims of accidents, is inevitable. Accordingly, the present study was designed to determine the effect of training through the simulation method (based on a scenario designed on the scene of a collective accident) on the level of knowledge and manner of performance of nursing students of Qom University of Medical Sciences. It is believed that the results of this educational method can identify the shortcomings and obstacles and reduce the existing problems in crisis management and triage when collective accidents occur by better planning.

\section{Materials and Methods}

This research is a semi experimental study, and the target community includes 70 nursing students studying in the junior and senior years of the School of Nursing and Midwifery of the Qom University of Medical Sciences. The researcher examined the level of knowledge and manner of performance in the triage of the injured resulting from a collective accident based on the simulation of 
the scene of accident. The level of effectiveness of the training sessions on the knowledge and performance of the students was then evaluated. The data of the study were obtained through a two-part questionnaire that included demographic information and evaluation of knowledge and also by carrying out a practical test on mockup models.

First, the administrative stages that included obtaining an introduction letter from the Deputy Dean for Research of the Qom University of Medical Sciences and presenting it to the School of Nursing and Midwifery were completed. Then the researcher obtained the necessary permission for the study. From the junior and senior student classes, two classes were selected at random. Then 70 students of these two classes were extracted for the study based on the random number table and the inclusion criteria. The potential samples were then explained the details of the study (manner of execution, purpose of the study, time of the study, benefits of the study, confidentiality of information and expression of ethical points). In addition, a specific time was given for asking questions and reading the informed consent form.

In the beginning and before the intervention, the level of scientific knowledge was measured by the knowledge questionnaire and the correct performance level by the designed mockup models. After training, the students were again tested for knowledge and performance. The researcher-made tools consisted of knowledge questionnaire that included 10 questions of four options each (maximum 10 points). The content of the questions was taken from the materials presented and discussed in the related class (the said questionnaire had been extracted by relevant professors from sources related to the subject of training). The reliability of the questionnaire was obtained to be equal to 0.87 based on Cronbach's Alpha coefficient. The content's validity was examined by the professors of the Qom University of Medical Sciences and the experts from the Qom Center for Accidents Management and Medical Emergencies. After undergoing some modifications, the questionnaire was approved.

The correct performance of triage was examined by using 10 mockup models designed for the study. Based on the injury inflicted and the level of damage, they were written on different limbs of the mockup model and the student was required to carry out the accident scene triage based on the START criteria. START is one of the most common triage methods performed at the scene of disasters and involves simple triage and rapid treatment. In this method, the four colors of red, yellow, green, and black are used to highlight the priorities of urgent, de- layed, outpatient and death, respectively. In the first stage, the ability of the injured person to walk is evaluated.

A patient with the ability to walk is placed in the third priority specified by the color green and does not need emergency treatment and will be examined again in the secondary triage. In case the injured person is unable to walk, his respiratory status is examined. In case his breathing count is less than 30 times per minute, capillary return and following the instructions are examined and in case any of them were abnormal the victim would receive the red card, otherwise the yellow card would be assigned to that victim and that will be considered second priority. The black card is assigned to the patient who in the initial examination was not breathing and did not resume spontaneous breathing on changing his/her position and maneuvering the patient's air way. In this method, the time to examine each victim is 30 seconds, and it involves only two steps of opening the patient's air way and controlling the bleeding.

Performing the practical test was in this way that in a specific location that simulations has been done based on an accident scene, ten mockup models on which the vital status and the type of injury were written on the injured organ or limb, in ten specific spots that consisted of prefabricated obstacles such as automobile, gutter, items separated from the automobile and personal effects of the automobile's occupants, a layout was placed and then five minutes of time, that is 30 seconds per victim, was given to the students [23] to place the triage card bearing the correct color on each mockup model, and in the end as for each correct case one point was given as score to the student. The total score in this section was 10 points, and no score was given to the error cases.

Based on the academic curriculum of the school of nursing, a training workshop was conducted for the students in two sessions of two hours each and based on the START triage. Course discussion was based on the curriculum of emergency nursing in crisis and unforeseen incidents in which the students, while learning the principles and concepts of nursing in emergencies, by benefitting from creative thinking skills, proper communication and the problem-solving process, they became familiar in practice with the triage process in the pre-hospital environment. The outline of the subject materials included nursing principles in emergencies and disasters, providing solutions and nursing interventions based on nursing diagnosis in pre-hospital emergencies, familiarity with triage, defining the triage and its types, the role of nurse in the patients triage, examining and identifying the patients in emergency situation, and providing pre- 
hospital care based on decision-making priority process in the pre-hospital emergency $[18,24,25]$. To describe the data, the frequency tables were used, and the median index and standard deviations were used to describe the quantitative data. Percentages were used to describe the qualitative data. For analyzing the data, the paired t-test and independent t-test were used.

\section{Results}

In this study, 70 students in the third and fourth year of studies at the School of Nursing participated among whom 30 students were females and 40 students were males. The median and standard deviation of the students' knowledge before the test was $4.06 \pm 1.94$, and this level was $7.40 \pm 1.35$ after the training. The median and standard deviation of the practical test of the students before training was $4.90 \pm 1.6$, and this level was $8.30 \pm 1.5$ after the training. The comparison of the level of knowl- edge and the practical test of the students before and after the training showed that the difference is significant. The median and standard deviation of the students' practical test before the training was $2.97 \pm 0.81$ and after the training was $3.2 \pm 0.98$, indicating that the difference is not significant (Table 1).

The median and the standard deviation of the female students' knowledge before the training was $3.86 \pm 1.60$, and this level in the male students was $4.19 \pm 1.42$. Also, the median and the standard deviation of the female students after training was $7.45 \pm 1.22$, and this level in the male students was $7.34 \pm 1.45$. Therefore, the comparison of the level of knowledge of female and male students before and after training showed that the difference is not significant (Table 2)

The median and the standard deviation of the practical test of female students before training was $5.32 \pm 1.64$,

Table 1. Comparison of the median and the standard deviation of the knowledge and practical test and the time of practical test of the students before and after training

\begin{tabular}{|c|c|c|c|c|}
\hline Variable & & Median \pm Standard Deviation & $\mathbf{T}$ & $\mathbf{P}$ \\
\hline \multirow{3}{*}{ Knowledge } & Before & $4.06 \pm 1.94$ & \multirow{3}{*}{-14.20} & \multirow{3}{*}{0.001} \\
\hline & & & & \\
\hline & After & $7.40 \pm 1.35$ & & \\
\hline \multirow{3}{*}{ Practical test } & Before & $4.90 \pm 1.6$ & \multirow{3}{*}{-11.80} & \multirow{3}{*}{0.001} \\
\hline & & & & \\
\hline & After & $8.30 \pm 1.5$ & & \\
\hline \multirow{3}{*}{ Time of practical test } & Before & $2.97 \pm 0.81$ & \multirow{3}{*}{-1.40} & \multirow{3}{*}{0.17} \\
\hline & & & & \\
\hline & After & $3.2 \pm 0.98$ & & \\
\hline
\end{tabular}

Table 2. Comparison of the median and the standard deviation of the knowledge and the practical test of the students based on gender before and after training

\begin{tabular}{|c|c|c|c|c|c|}
\hline Variable & & Gender & Median \pm Standard Deviation & $\mathbf{T}$ & $\mathbf{P}$ \\
\hline \multirow{2}{*}{ Knowledge } & Before & $\begin{array}{l}\text { Female } \\
\text { Male }\end{array}$ & $\begin{array}{l}3.86 \pm 1.60 \\
4.19 \pm 1.42\end{array}$ & -0.76 & 0.44 \\
\hline & After & $\begin{array}{l}\text { Female } \\
\text { Male }\end{array}$ & $\begin{array}{l}7.45 \pm 1.22 \\
7.34 \pm 1.45\end{array}$ & 0.29 & 0.77 \\
\hline Practical test & Before & $\begin{array}{l}\text { Female } \\
\text { Male } \\
\text { Female } \\
\text { Male }\end{array}$ & $\begin{array}{l}5.32 \pm 1.64 \\
4.59 \pm 1.50 \\
8.05 \pm 1.86 \\
8.44 \pm 1.32\end{array}$ & -0.91 & 0.10 \\
\hline
\end{tabular}


and this level in the male students was $4.59 \pm 1.50$. Also, the median and the standard deviation of the practical test of female students after training was $8.05 \pm 1.86$, and this level in the male students was $8.44 \pm 1.32$. The comparison of the level of practical test of the female and male students before and after training showed that the difference is not significant (Table 2).

\section{Discussion}

The results of statistical analysis showed that the level of knowledge and performance of the students in triage before the training was weak. However, this level after the training stood at a good level, and the difference between the median of knowledge and performance in the triage was also significant (Table 1). This is an indicator of the effective and positive role of training in this test. The study by Farahi and colleagues showed that the median score of preparedness and accuracy in performing the triage before and after training have a significant difference with each other. In addition, this median number has significantly increased after the training [1]. In a similar study, Fuberg showed that training through simulation method can significantly increase the learning and performance of nurses in triage [26]. Chen showed that using tabletop exercise of START triage improves the ability to carry out the triage and reduces the mistakes in identifying prioritization of the injured [27]. The results of these studies with regard to the type of training (i.e., simulation method) and the derived results are consistent with the present study and confirm it.

On examining the median and the standard deviation of the time for practical test conducted on the students before and after the training, it became clear that there is a slight increase in the median score after the training. However, this increase in the median time for practical test is not statistically significant (Table 2). It is likely that this increase in time was due to the greater amount of attention the students paid for conducting a more correct and accurate performance of this test.

It was found that the difference in the median of the level of knowledge and the practical test of the female and male students before and after the training is not significant. The female and male students are on the same level with regard to knowledge and performance in the test of triage, and gender difference has no effect on creating difference and impact on the level of knowledge and performance of the students.

These results indicate that the level of students' knowledge, the manner of their performance in practice, and the time needed for conducting triage on patients are not related to the gender of the students. The results obtained by students in the triage tests do not have any relation with their gender. Also, due to the direct connection between the level of knowledge of the students after the training and the practical test after the training, it can be said that the level of knowledge of the students has affected their practical work. In their study, Haghdoust and colleagues showed that the median performance of nursing students in carrying out the triage and also their knowledge have increased after the training.

This indicates the positive effect of training and the need for implementing coherent and planned trainings in this field [12]. In their research, Sarykaya and colleagues also reached the conclusion that the decisions by the emergency ward doctors and clinical paramedics in the pre-training stage had low consistency while after training, these decisions showed relative improvement in consistency. In other words, the median consistency recorded by emergency ward doctors and clinical paramedics if the symptoms are diagnosed from the low amount at the pre-training stage becomes moderate in the post-training stage [28].

The research conducted by Moadab and Bahrami showed that $86 \%$ of emergency units had not taken the triage training course and $98.2 \%$ of those units do not know their main responsibility because the required culture building in this regard has not taken place in the universities. Moreover, when accidents happen, the nurse takes on the role of an executive. Results also indicate that $68.8 \%$ of units under the study believed that a unified triage system has not been included in the health and treatment system, and multiplicity in performing the triage would weaken the personnel's efficiency [29].

In order to achieve proper skills in the treatment personnel, especially in pre-hospital technicians present in the first stage of dealing with accidents and disasters, the theoretical aspects and basic knowledge related to triage should be sought, identified and perfected. This should be followed by the organization of coherent training courses by organizing practical maneuvers and simulation of the scene of accidents to enhance the skills and efficiency of the personnel.

\section{Conclusion}

The results of the study showed that training through simulation performed on the mockup model has been effective on the preparedness of nurses in performing the triage at the time of occurrence of accidents and disas- 
ters. This training has improved the nurses' preparedness in this regard. Therefore, it is recommended that considering the importance of triage at the time accidents and disasters and medical emergencies, training courses should be organized to increase the knowledge of the personnel that would lead to an increase in the quality of the manner by which the triage is performed in pre-hospital emergencies. It is, thus, recommended that for increasing the generalizability and the power of the study, similar studies should be carried out with a larger number of samples and with protracted follow-up.

\section{Acknowledgments}

This study was approved by the School of Nursing and Midwifery of Qom University of Medical Sciences under the code number 95681 in 2017. The cooperation and financial assistance of the Research Deputy of Qom University of Medical Sciences are gratefully appreciated.

\section{Conflict of Interest}

The authors declared no conflicts of interest.

\section{References}

[1] Faraji A, Khankeh HR, Hosseini MA, Abdi K, Rezasoltani P. Effect of simulated training course on preparedness of nurses to do pre-hospital triage. Journal of Health Promotion Management. 2013; 2(4):24-9.

[2] Rostampour M, Kalroozi F, Pishgooie A, Aliyari S, et al. The effect of triage education by pre advance-organizer model on the knowledge staff disaster team nurses. Military Caring Sciences. 2016; 3(3):141-8. doi: 10.18869/acadpub.mcs.3.3.141

[3] Brussels B. University Tecatholique de Louvain centre for research on the epidemiology of disasters 2012. Brussels: Centre for Research on the Epidemiology of Disasters.

[4] Vafaei A. [Hospital disaster planning (Persian)] [PhD dissertation]. Tehran: Shahid Beheshti Medical University; 2010.

[5] Tadrisi SD, Siavash Vahabi Y, Ghayem SH, Ebadi A, Daneshmandi M, Saghafinia M. Comparing the effect of triage education in lecture and multimedia software on nurses learning. Iranian Journal of Critical Care Nursing Spring. 2011; 4(1):7-12.

[6] Djalali A, Khankeh H, Öhlén G, Castrén M, Kurland L. Facilitators and obstacles in pre-hospital medical response to earthquakes: A qualitative study. Scandinavian Journal of Trauma, Resuscitation and Emergency Medicine. 2011; 19(1):30. doi: 10.1186/1757-7241-19-30

[7] Mirhaghi AH, Roudbari M. [A survey on knowledge level of the nurses about hospital triage (Persian)]. Iranian Journal of Critical Care Nursing. 2011; 3(4):167-74.
[8] Aghababaeian H, Sedaghat S, Taheri N, Mousavi SA, Habibi Moghadam M, Pourmotahari F. Evaluating knowledge and performance of emergency medical services staff regarding pre-hospital triage. Iranian Journal of Emergency Medicine. 2017; 4(2):63-7.

[9] Sabzevari SA, Ghanbarzahi NE, Darban FA. The overall concordance of triage level between emergency medical technicians, triage nurses and instructor. Medical-Surgical Nursing Journal. 2015; 4(2):23.

[10] Jenkins JL, McCarthy ML, Sauer LM, Green GB, Stuart S, Thomas TL, et al. Mass-casualty triage: Time for an evidencebased approach. Prehospital and Disaster Medicine. 2008; 23(1):3-8. doi: 10.1017/s1049023x00005471

[11] Jakeway CC, LaRosa G, Cary A, Schoenfisch S. The role of public health nurses in emergency preparedness and response: A position paper of the association of state and territorial directors of nursing. Public Health Nursing. 2008; 25(4):353-61. doi: 10.1111/j.1525-1446.2008.00716.x

[12] Haghdoust Z, Safavi M, Yahyavi H. [Effect of triage education on knowledge, attitude and practice of nurses in Poursina educational and therapeutic emergency center in Rasht (Persian)]. Journal of Holistic Nursing and Midwifery. 2010; 20(64):14-21.

[13] Fatemi S. Disaster reduction and management in natural disasters. Paper presented at the National Conference on Promotion Strategies of Crisis Management in Hospitals. 29-30 August 2006; Zanjan. Iran.

[14] Ghanbari V, Maddah SS, Khankeh HR, Karimloo M. The effect of a disaster nursing education program on nurses' preparedness for responding to probable natural disasters. Iran Journal of Nursing. 2011; 24(73):72-80.

[15] Brannigan L, Witwer S, Rudel P, Young A. Simulation education in mass-casualty incident preparedness. Clinical Simulation in Nursing. 2006; 2(2):e69-e74. doi: 10.1016/j. ecns.2009.05.027

[16] Sedaghat S, Aghababaeian H, Taheri N, Moghaddam AS, Maniey M, Ahvazi LA. Study on the level of knowledge and performance of North Khuzestan medical emergency 115 personnel on pre-hospital triage. Iranian Journal of Critical Care Nursing. 2012; 5(2):103-8.

[17] Soloki M. Knowledge and practice of the city of Zabol emergency medicine personnel about triage before and after training. Paper presented at the 2nd Iranian Congress on Emergency Medicine, 29-31 May 2007; Tehran, Iran.

[18] Tabatabai A, Mohammadnejad E, Salari A. Nursing students' awareness of triage in the emergency ward. Jorjani Biomedicine Journal. 2014; 1(1):30-4.

[19] Javadi S, Salimi T, Sareban MT, Dehghani MA. Knowledge and practice of nurses regarding patients' triage in emergency department. Iranian Journal of Emergency Medicine. 2016; 3(1):15-22.

[20] Kalantarimeibidi M, Yadollahi A, Esfandiari S. The effect of education on the knowledge and practice of emergency department's nurses regarding the patients' triage. Iranian Journal of Emergency Medicine. 2014; 1(1):40-4.

[21] Malekshahi F. Capabilities and limitations and social crisis in Shohada Hospital of the city of Khorramabad. Journal of Critical Care Nursing. 2009:29-34 
[22] Pazargadi M, Sadeghi R. Simulation in nursing education. Iranian Quarterly of Education Strategies. 2011; 3(4):161-7.

[23] Arslanian Engoren C, Eagle KA, Hagerty B, Reits S. Emergency department triage nurses' self-reported adherence with American College of Cardiology/American Heart Association myocardial infarction guidelines. Journal of Cardiovascular Nursing. 2011; 26(5):408-13. doi: 10.1097/ jcn.0b013e3182076a98

[24] Shojaeizadeh D. Models of behavior study in health education. Tehran: Administration of Health Education; 2000.

[25] Hedayati H, Mogharrab M, Moasheri N, Sharifzadeh G. Studying of BUMS'students' knowledge about hospital triage in 2011. Modern Care Journal. 2013; 9(3):237-44.

[26] Furberg RD, Kizakevich PN, Marcozzi DE, Hubal R, Grantlin S, Holloway J, Duncan S. Analysis of interdisciplinary, simulation-based triage training for disaster preparedness and response. Prehospital and Disaster Medicine. 2007; 22(2):s5.

[27] Chen KC, Chen CC, Wang TL. The role of tabletop exercise using START in improving triage ability in disaster medical assistance team. Annals of Emergency Medicine. 2003; 1(2):78-84

[28] Sarikaya S, Soysal S, Karcioglu O, Topacoglu H, Tasar A. Paramedics and triage: Effect of one training session on triage in the emergency department. Advances in Therapy. 2004; 21(5):329-34. doi: 10.1007/bf02850037

[29] Mahjoob Moadab H, Bahrami F. [Investigating the challenges and problems of triage execution from nurses' viewpoints in the selected educational center (Persian)]. Paper presented at the 3rd International Congress on Health, Medication and Crisis Management in Disaster. 12-14 December 2006; Tehran, Iran. 